This is an electronic reprint of the original article. This reprint may differ from the original in pagination and typographic detail.

Please cite the original version: Votkin, T. ; Wallenius, L. ; Lehto, T. \& Halsas, M. (2019) Pedagogical Underpinnings of a Multi-Disciplinary Language Learning Portal - the Connection Between Theory and Practice, INTED2019 Proceedings, pp. 2747-2753. 


\title{
PEDAGOGICAL UNDERPINNINGS OF A MULTI-DISCIPLINARY LANGUAGE LEARNING PORTAL - THE CONNECTION BETWEEN THEORY AND PRACTICE
}

\author{
T. Votkin ${ }^{1}$, L. Wallenius ${ }^{2}$, T. Lehto ${ }^{3}$, M. Halsas ${ }^{2}$ \\ ${ }^{1}$ Aalto University (FINLAND) \\ ${ }^{2}$ Haaga-Helia University of Applied Sciences (FINLAND) \\ ${ }^{3}$ Laurea University of Applied Sciences (FINLAND)
}

\begin{abstract}
This paper discusses how pedagogical aspects have affected the technical choices in constructing the multi-disciplinary and open-access digital language learning portal called Svenskstudier $i$ bufféformat. The portal is being developed in one of the teacher teams in DIGIJOUJOU project, a national development project for digitalizing second language learning in higher education in Finland financed by Ministry of Education. The developing team represents three higher education institutions: Aalto University, Haaga-Helia University of Applied Sciences and Laurea University of Applied Sciences. The aim of the portal is to empower and engage students to study Professional Swedish in higher education in the virtual environment within their own discipline by their own choices.
\end{abstract}

The pedagogical underpinnings of the portal are task-based learning, content-based instruction, flipped learning, blended learning, communicative language learning as well as content and language integrated learning (CLIL). Other methodologies considered are constructivism and learning in taskbased environment. All these pedagogical approaches support the higher education students' personal curricula and language studies are thus strongly integrated in subject matters of the degree programs. Our paper aims at combining language studies and degree studies contents in a flexible and motivating way.

The objective of the study portal is to motivate students and give them more responsibility and autonomy of their own learning i.e. student empowerment. Students are active content creators, not passive receivers of information. The activities on the portal encourage students to seek information, to process information in various ways to end up in an appropriate output. During the learning process, students are encouraged to choose between a range of digital tools, i.e. open source tools, web conferencing software, video production and editing tools, games and quizzes and message applications, not to forget the more traditional ways of output.

The connection of theory and practice, and methodological and technological choices are presented via concrete examples of individual activities on the portal. Various digital tools have been tested and used and the aim is that each task requires the command of at least one digital tool, which supports the study process and learning outcome in a natural way. Furthermore, student/teacher feedback and experience will be discussed and taken into account as the portal is under construction during 2019.

Keywords: Digital learning, task-based language learning, higher education, open source portal.

\section{INTRODUCTION}

Within the Finnish national higher education DIGIJOUJOU-project [1] we have developed an openaccess multi-disciplinary portal, called Svenskstudier $i$ bufféformat, for learning Swedish, the second official language in Finland. All higher education degrees in Finland have obligatory B1-C2 -level studies in Swedish if Swedish is not the student's native language. The learning portal functions as an activity bank, and it has instructions and ideas for both teachers and students on how to use the portal and how to combine it with the learning environment of the students' own university.

The portal consists of tasks, which students select based on their own curricula requirements as well as their discipline and branch-specific fields. They also choose which language skills they wish to practice. The possibility to make one's own choices increases the motivation of the students. After choosing their own tasks students make a learning agreement and submit it for the teacher's approval. In the next phase, students seek information, process it and use appropriate digital tools to create and submit the outcome of the task. The submission may be a traditional paper, a video, an infographic, a 
mind-map or a presentation created with digital and graphic tools. Furthermore, teachers may create various combinations of online learning, chats, virtual and face-to-face meetings for the outcome presentations. Consequently, the portal enables creating a social context as several tasks can be prepared in teams, or at least presented and discussed in teams. The portal is flexible and it involves practicing various language skills keeping the digital approach and the student's degree substance contents in mind.

When planning the portal and the individual tasks, we had the following theoretical frameworks in mind: task-based learning, content-based instruction, flipped learning, blended learning, communicative language learning as well as content and language integrated learning (CLIL). In section 2 we will explain how these theories have influenced the creation of the portal. After that we will discuss the connection between theory and practice in detail, i.e. we explain the pedagogical theory behind selected tasks and which digital solutions support the student to achieve the best possible outcome of the tasks. Following the concrete examples, we will discuss the technical solutions and the digital aspects from two different perspectives; the teacher and the student. In the conclusions we discuss the advantages of the open-access multidisciplinary portal and its further development.

\section{METHODOLOGY}

The pedagogical approach of the portal Svenskstudier $i$ bufféformat [2] can be placed under the umbrella of Communicative Language Teaching (CLT). The objective of CLT is that students learn and practice communicative competence for their professional careers. The goal is to prioritize the students' needs and empower them to choose interesting and relevant topics. The central idea of CLT is that learning happens through peer input and during interaction with fellow students [3]. Communicative competence entails, among other things, knowledge of how to use language for different purposes, and the ability to understand and to produce texts of various types and registers [4]. Because enabling the students gain communicative competence is one our aims, we offer different types of tasks that allow the learners to gain experience with various types of texts.

Content Based Instruction ( $\mathrm{CBI}$ ) entails learning a target language through content. Learning is built around relevant contents rather than linguistic syllabuses. [5]. Learning a language is seen as tool for further learning rather than a goal in itself. Motivation is considered a significant factor, and the aim is to provide learners with motivating tasks. Stimulating content is a key factor in motivating students. In our tasks, students are encouraged to select interesting and relevant perspectives to the content and to seek information. The aim is not to study isolated language fragments, but to learn the language in a specific context. When students work on the content, e.g. search information and produce output, they have opportunities to listen, read, write and/or speak the target language. The focus throughout the process is on the content and thus the language learning is a byproduct of the process. [6]

Task-Based Language Learning (TBLL) is an sub-category of Content Based Instruction [7] Within applied linguistics, a task can be defined as an act that accomplishes something by using the target language as a tool of communication. [8] A task could consist of e.g. booking a train ticket or visiting a doctor. Ellis [8 ibid.] emphasizes the importance of social interaction and communication in TBLL. The approach is widely known through N. Prabhu and his work in India where he observed that students learned the target language both when working with concrete tasks as well as when focusing on the linguistic aspects of the language such as grammar [9]. The portal consists of tasks that the students complete individually, in pairs or in groups The tasks can be done regardless of time and space, and they can be completed in the learner's own pace but as scheduled in an individual or group course plan.

Another language learning theory applied on the portal is flipped learning. Student autonomy is a central concept promoted in flipped learning and thus students take responsibility of their own learning. At the same time learning is regarded as a social event [10]. Flipped learning entails that students work on selected themes and related materials prior to class. The work is then discussed and outputs are inspected in class [11]. Talbert (ibid.) emphasises that flipped learning is more than using certain techniques, and he sees it rather as a methodology. The tasks available on the portal are suitable for flipped learning, since the idea is that the students work on tasks at home, and then present and discuss them in class or online with other students and the teacher.

Blended learning is a term for learning where students participate in face-to-face teaching in addition to independent work [12]. It is important that students have control over time, space and the pace of 
study. Students are more in charge with their own learning and able to control it, which constitutes an important aspect of blended learning. This is a significant factor that distinguishes blended learning from technology-rich instruction. The tasks on our portal are designed to be completed online to certain extent. The task instructions are online and encourage students to use online resources. Students can then also use online tools to process the data and share the outcomes. Finally, the students are required to present their outcomes in the classroom (face-to-face or virtual) and discuss their work with their peers.

Content and Language Integrated Learning (CLIL) focuses on content and an additional language is used for learning it [15]. CLIL often involves experts of content and language. According to CLIL learning takes place in specific contexts starting with 1) the content and focusing then on 2) communication, 3) cognition and 4) culture. Subject matter and language are integrated. Subject matter is learnt by acquiring subject knowledge and constructing own understanding. Cognition develops as own understanding is created and topics analysed also linguistically. Furthermore, learning takes place in a social context where interaction is a vital part. Culture plays a role when considering specific cultures related with language use [16]. Relevant tasks are vital, and according to Dale and Tanner [15], Bloom's new taxonomy is a useful framework for creating CLIL tasks. The six steps of Bloom's new taxonomy are remembering, understanding, applying, analysing, evaluating and creating. This framework is beneficial for the cognitive process and provides context for learning language for higher-level thinking (i.e. analysing, evaluating and creating). Benefits of CLIL are that it often increases motivation levels. Learners benefit cognitively from the use of an additional language. Learners of foreign or second languages might not always have many possibilities to practice analytical skills involving higher level thinking and learning. Cognitively the benefits of CLIL also lie in the fact that learners often remember the learning activities with challenges. Most of the tasks on the portal can be considered to be CLIL applications as the objective of learning is not only language.

\section{RESULTS}

In this section we will discuss the connection, theory and practice of different language learning approaches as well as some example tasks on the language learning portal Svenskstudier $i$ bufféformat. We also discuss the digital aspects of the portal from two perspectives: teacher's and the student's.

\subsection{The Connection between theory and practice}

\subsubsection{Communicative Language Learning}

The activity Reklamationsdialoger (Customer complaint) dialogues is an example of communicative language teaching CLT in the portal in section 3 Kunden $i$ focus (Client in focus). The task concentrates on communicative competence necessary in customer complaints. The students have the freedom to choose the topic of the complaint relevant to their own field. The task includes peer input and interaction with fellow students on a digital portal provided by the student's own institute. Thus CLT is clearly visible in the pedagogical planning of the task.

As we are talking about a dialogue, this task must be done in pairs. The goal of the task is to help the student to cope with authentic complaint discussions, to consider the situation, to learn to be polite and to acquire appropriate vocabulary when dealing with complaints. The students have to prepare to the task by studying background material of complaints, both branch articles, complaint instructions and vocabulary lists in Quizlet-application. After that the students create a professional complaint situation which could be relevant in their future work, write a complete manuscript and then play the dialogue and record it. The complaint video will be shared to other student pairs and to complete the task the students need to comment each other's videos from given viewpoints.

The following digital competences will be trained in this task: 1) Tools for learning words: Quizlet and ready-made exercises in the portal; 2) Video filming, editing and publishing tools (mobile phone applications, iMovie, YouTube, Kaltura, institutional publishing portals) and 3) Discussion forums (Moodle, Optima).

\subsubsection{Content Based Instruction (CBI)}

Activities Sociala medier och marknadsföring (Social media and Marketing) and Webbutiker (Online Trading), are examples of $\mathrm{CBI}$ implementation. The language learning takes places through content. 
The language is a tool and learner motivation is important. Therefor the students can freely select the target of their web shop analysis and the companies to be analysed. This has an effect on the motivation level and can often be seen in the ambition level and results.

First, the students familiarise themselves with the concepts at hand (social media in Scandinavia/own field, e-business). They create their own definitions of the concepts with examples in writing and in discourse (chat, face-to-face meeting, online chat). This is the phase where they start to remember, understand and apply the concepts. They then continue to apply, analyse and create as they plan how to implement the task. In the end, the students create presentations, analyses and videos on their own work, and discuss and evaluate other students' work.

These activities entail use of the following digital competences: 1) generation of multimodal texts: creating a multimodal report, presentation graphics e.g. Prezi, AdobeSpark; 2) tele-conferencing and chat: presenting the report and discussing and analysing other students' reports; suggested tools e.g AdobeConnectPro and Zoom; and 3) video filming and editing: creating a video; suggested programmes and applications e.g. iMovie, Movavi, AdobeSpark, Lucidpress.

\subsubsection{Task-based Language Learning}

The activity Att söka jobba i Sverige (Find a job in Sweden) is an example of a task where the student completes a task using the target language as a tool. In the activity the student is asked to look for information about available work possibilities within their own field. When they find a suitable job, they are supposed to find out more details about it. Alternatively, they can contact a company they are interested in working for and ask more about future career possibilities. In addition to finding a job, the student can look for suitable housing options, free time activities, health care, childcare or any other special wishes or needs they might have. Ellis [8] emphasizes social interaction in task-based language learning, and it is encouraged that the student interacts in various ways with authentic people in real life contexts while working on the task. Finally, the student can present the new information and discuss it with peer students in the target language. The social interaction can happen via email, chat, phone, video conference or meeting in person with key people. According to the principles of TBLL, the focus is on communication and competing the task, not on the linguistics aspects of their output. In this activity the student can practice information seeking skills, written and oral communication skills, and presentation skills.

\subsubsection{Flipped Learning}

The activity Reklamfilmanalys (Analysis of an advertisement) video is an example of flipped learning, which gives the student autonomy and responsibility of the learning process. In the task the student finds the study material and becomes acquainted with the theoretical background prior to classroom meeting. Then it is easier to process the information professionally in class, and after the class the student needs to go back to the outcomes of the whole study group. So the task contains the elements of flipped learning - pre-activity/activity/post-activity.

The goal of the task is to become acquainted with advertisements in the student's field and to be able to analyse them professionally. For that purpose students have to find an interesting video advertisement carrying information on their own field. This task can be connected to eventual marketing courses if such are available in the degree program. In addition, the students have to read background material on constructing successful product presentations as well as instructions for creating effective marketing videos. So when the students come to class (virtual or live) they have familiarized with theory and have chosen the video for analysis. In class they work with their professional analyses (alone/in pairs/in groups) showing that they know the theory behind, and the outcome can be presented either as a video or using various presentation tools. The presentation of the outcome is challenging, as they have to include videoclips between their own recorded or visual comments to be able to analyse in detail. The post-activity includes watching and commenting the other students' outcomes.

When it comes to digital competence needs this task requires good command of recording and editing tools as well as mastering graphic presentation tools and publishing tools. The following tools are suggested for the students: YouTube, iMovie, AdobeSpark, Adobe Clip, Sway, PowerPoint and Prezi. In the post-activity a discussion forum is needed. 


\subsubsection{Blended learning}

Almost all the activities in Svensksstudier i bufféformat portal are catered with some model of blended learning and many of them are based on more than one alternative model. The goal is that students are always able to choose the most suitable model(s), which normally means a hybrid of different options in the learning processes.

The activity På mässan (On an exhibition) is an example of how students can use e g. Rotation model during their learning process and while they prepare for the final face of the exercise. In this activity students need to plan and accomplish their own role and actions on an expo stand at a hypothetical career fair. The goal is to learn to represent a company/an organization and to act as a potential job seeker on a career fair. Students need to search for specific and actual information online, train their own representation skills, and be in active contact with the fellow students (and the instructing teacher) both online and face-to-face. The activity can be completed in a normal classroom or in a high-quality online communication portal (e g. Zoom). The only requirement is that students actively communicate before and especially during the final face of the exercise (simulation of a recruitment fair). The fair simulation requires also a digital presentation on the "stand" and students can free choose the tools and media they prefer.

This activity can easily be connected with almost any kind professional studies on a bit more advanced language learning level.

\subsubsection{Content-integrated language learning - CLIL}

Activities Mystery shopping och kundresan (Mystery Shopping and Customer Experience) and Storytelling och rapportering (Storytelling and reporting) are examples on how CLIL is embedded in our portal. The learning contexts are customer service, B2C or B2B, in any branch or discipline and storytelling. First, the students familiarise themselves with the concepts. They give own definition of the concepts. This involves cognitive thinking and communication as the concepts are explained and own understanding created.This is the phase where students start to remember, understand and apply. Then they continue to apply, analyse and create as they plan how to implement the task. In the end, students create reports, analyses, presentations, videos on their own work, and discuss and evaluate other students' work. Here the communication and interaction continues, and culture is considered in discussions and also according to the media choices.

These two activities entail the use of some of the following digital skills: 1) generation of multimodal texts: creating a mystery shopping template, multimodal report, presentation; suggested digital tools and applications such as AdobeSpark, Canva; 2) tele-conferencing and chat: presenting the report and discussing and analysing other students' reports on-line or in class; suggested tools: AdobeConnectPro, Zoom, Skype and 3) video and video editing: creating a video; suggested programmes and applications iMovie, Movavi, Adobe Spark, Lucidpress.

\subsection{Digital aspects of the portal from different points of view}

In this section we will discuss the technical solutions of the portal and discuss the digital aspects from two perspectives; the teacher and the student.

\subsubsection{Technical solutions of the portal}

The portal Svensksstudier i bufféformat is powered by WordPress. We have chosen WordPress as the technical solution for several reasons. First, it is an open portal accessible to any Internet user without need to log in. The portal and the individual activities can be found through search engines. Secondly, we can use a hierarchical disposition on the portal, which makes it easier to navigate. WordPress enables us to tag the activities with relevant keywords to help the student to find suitable tasks. Being able to track which pages are visited, gives us valuable information about how the students use the portal and to further develop it so that it can cater for the needs of our students even better.

\subsubsection{Digital aspects from the teacher point of view}

The aim of the portal is to serve many different teachers at several institutions of higher education, where Swedish is taught for Finnish speakers. The fact that the portal is open for anyone, makes it easier even for the teachers to use it. The open source portal and requirement to apply various digital tools in the tasks are expected to motivate and engage the students. 
One of the disadvantages of this type of technical solution might be that there is no place for student output submission nor feedback, and they need to be done on a different forum. Nevertheless, with the help of this portal it is easier for the teacher to promote digitalization, which is one strategic goal within education also within higher education. Digitalization is for example mentioned in the Aalto university strategy as one of the central objects [16].

\subsubsection{Digital skills from the student point of view}

With the help of the Svensksstudier i bufféformat portal the students are able to practice different kind of language and work life skills that are also central in the Common European Framework of Reference for Languages (CEFR) [17,18]: information seeking, both written and spoken interaction, speaking, reading, listening and mediation. Furthermore they can learn to produce multimodal texts, different types of visuals, like presentations, ads and posters. When interacting with fellow students or with representatives of different companies and organizations they can practice video conferencing skills and use for example chats for communication and requiring information. Good communication is the main focus in all the activities, and therefore students are encouraged to learn adequate vocabulary and to master the basic language structures well. The portal will provide digital tools for both learning vocabulary and grammar.

The students are also encouraged to use different types of digital tools while working on their activities and when presenting them for others. Figure 1 illustrates such tools including search engines like Google, tools to generate multimodal texts like MicrosoftOffice, AdobeSpark, Canva and Prezi, teleconferencing and chat tools like for presenting own work and discussing and analyzing other students' work like AdobeConnectPro, Zoom, Skype, Moodle and Blackboard. One essential skill that the portal encourages students to acquire is video production and video editing. That can be practiced with the help of iMovie, Movavi, AdobeSpark, Lucidpress, ThingLink or Panopto.

\section{CONCLUSIONS}

In conclusion, the tasks on Svensksstudier $i$ bufféformat make use of different learning approaches and combine them. It is evident that the underlying pedagogical theories are student centred (CLT, TBLL, Flipped learning, Blended learning), and focus on integration of content (CLT, CBI, TBLL, CLIL). Communication and learning via social communication are included in the theories. As such the portal caters different types of learners as well as instructors, and various disciplines.

Benefits of the portal are multi-disciplinary contents, cross-institutional learning groups, flexibility of time and space, self-directed learning and open source learning content management system. Free of charge for non-commercial purposes (CC by NC) licencing is clearly a benefit.

Students are the main user group of the portal and therefore it is vital that feedback be collected and used to develop the portal to help students navigate the portal and engage in the tasks. Furthermore, the portal should encourage students to use digital tools and materials in learning and communication. The visual outlook of the portal might also be improved as might be more attracted to a modern and visually agreeable portal. The digital tools suggested for task output need to be easily accessible and mostly free of charge. Manuals and instructions might also enhance user-friendliness.

We hope that the portal will serve both students and teachers at various institutions within the higher education in Finland to promote digitalization in education and in language learning according to the current national guidelines and educational strategies.

\section{ACKNOWLEDGEMENTS}

We wish to thank the DIGIJOJOUJOU project and our respective universities and universities of applied sciences for the financial support to with this project and to contribute to the INTED 2019 Conference.

\section{REFERENCES}

[1] DIGIJOUJOU project. Retrieverd from: https://blogs.aalto.fi/digijoujou/

[2] Svensksstudier i buffétformat -Learning Retrieved from :https://svenskstudieribuffeformat.wordpress.com 
[3] W. Littlewood, Communicative language teaching: An introduction. Cambridge University Press, 1981.

[4] J.C. Richards, Communicative language teaching today. SEAMEO Regional Language Centre, 2005.

[5] J. Richards, T. Rodgers, Approaches and Methods in Language Teaching. Cambridge: Cambridge University Press, 2014.

[6] D. Brinton, "Content-based instruction". In D. Nunan (Ed.), Practical English Language Teaching. New York: McGraw Hill, 2003.

[7] Y. J. Basim, M. T. Yousif, "A Content- Based Instruction Versus Task-Based Approach to Teaching Legal English: An Experimental Study", In University of Sharjah Journal for Humanities \& Social Sciences, Volume 9, No. 3 pp. , 2012. Retrieved from http://www.sharjah.ac.ae/en/Research/spu/JournalHSS/Documents/V9/N3/Basim\%20Yahya\%20J asim.pdf 18.9.2018.

[8] R. Ellis, Task-based Language Learning and Teaching. Oxford: Oxford University Press, 2003.

[9] N.S. Prabhu, Second Language Pedagogy. Oxford: Oxford University Press, 1987.

[10] Toivola \& al. (2017), Flipped learning - Käänteinen oppiminen, Edita, 2017

[11] R. Talbert, Flipped Learning - A Guide to Higher Learning Faculty. Stylus Publishing, LLC, 2017.

[12] Great Schools Partnership. 2013. Blended learning. Last accessed online 18.9.2018. Retrieved from http://edglossary.org/blended-learning/

[13] C. Maxwell, What blended learning is and isn't. Blended Learning Universe, 2016. Retrieved from https://www.blendedlearning.org/what-blended-learning-is-and-isnt/ 20.9.2018.

[14] Teaching with Technology. Online workshop series 2012-2013. Retrieved from https://teachingwithtech.Iss.wisc.edu/m3w1.htm. 21.9.2018.

[15] L.Dale, R.Tanner. CLIL Activitities. Cambridge: Cambridge University Press, 2012.

[16] The 4 C's model - Do Coyle. CLIL me softly. Retrieved from https://clilingmesoftly.wordpress.com/clil-models-3/the-4-cs-model-docoyle/ 2.1.2019.

[17] Aalto University Strategy: Retrieved from https://www.aalto.fi/sites/g/files/flghsv161/files/201804/aalto-yliopisto_strategy_english.pdf 7.1.2019.

[18] CEFR levels for language learning: Retrieved from https://rm.coe.int/CoERMPublicCommonSearchServices/DisplayDCTMContent?documentld=090 $000168045 b b 52$ 8.1.2019.

[19] CEFR new descriptions: Retrieved from https://rm.coe.int/cefr-companion-volume-with-newdescriptors-2018/1680787989 8.1.2019. 